\title{
Steel fibers for replacing minimum reinforcement in beams under torsion
}

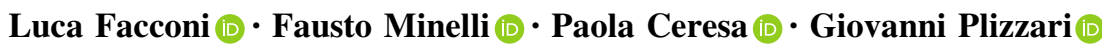

Received: 8 April 2020/Accepted: 30 December 2020/Published online: 22 January 2021

(C) The Author(s) 2021

\begin{abstract}
This paper concerns an investigation on six large-scale Steel Fiber Reinforced Concrete (SFRC) beams tested in pure torsion. All beams had longitudinal rebars to facilitate the well-known space truss resisting mechanism. However, in order to promote economic use of the material, the transverse reinforcement (i.e. stirrups/links) was varied in the six large scale beams. The latter contained either no stirrups, or the minimum amount of transverse reinforcement (according to Eurocode 2), or hooked-end steel fibers $\left(25\right.$ or $50 \mathrm{~kg} / \mathrm{m}^{3}$ ). Material characterization were also carried out to determine the performance parameters of SFRC. The results of this study show that SFRC with a post-cracking performance class greater than 2c (according to Model Code 2010) is able to completely substitute the minimum reinforcement required for resisting torsion. In fact, the addition of steel fibers contributes to significantly increase the maximum resisting torque and maximum twist when
\end{abstract}

L. Facconi · F. Minelli ( $₫)$ · G. Plizzari

University of Brescia, Brescia, Italy

e-mail: fausto.minelli@unibs.it

L. Facconi

e-mail: luca.facconi@unibs.it

G. Plizzari

e-mail: giovanni.plizzari@unibs.it

P. Ceresa

RED Risk Engineering + Development, Pavia, Italy

e-mail: paola.ceresa@redrisk.com compared to the same specimen without fibers. Moreover, SFRC provides a rather high post-cracking stiffness and a steadier development of the cracking process as compared to classical RC elements. This phenomenon improves beam behavior at serviceability limit state. The experimental results are critically discussed and compared to available analytical models as well as with other tests available into the literature.

Keywords Torsion in beams - Steel fiber reinforced concrete $\cdot$ High strength steel fibers $\cdot$ Experimental tests $\cdot$ Torsional rigidity $\cdot$ Minimum reinforcement

\section{List of symbols}

$A_{\mathrm{c}} \quad$ Gross area of the concrete section

$A_{\mathrm{o}} \quad$ Area enclosed within the mean-wall center line of the equivalent thin-walled section

$A_{\mathrm{sl}} \quad$ Total area of longitudinal reinforcement

$A_{\text {sw }} \quad$ Total cross-sectional area of transverse reinforcement

$A_{\text {sw }}^{\prime} \quad$ Cross-sectional area of one leg of a stirrup

$b \quad$ Width of the beam cross section

CMOD Crack mouth opening displacement

d Effective depth

$E_{\mathrm{cm}} \quad$ Mean Young's modulus of concrete

$f_{\mathrm{cm}} \quad$ Mean cylindrical compressive strength of concrete

$f_{\mathrm{ctm}} \quad$ Mean tensile strength of concrete

$f_{\text {ck }} \quad$ Characteristic cylindrical compressive strength of concrete 
$f_{\mathrm{L}} \quad$ Mean value of the limit of proportionality of concrete

$f_{\mathrm{R}} \quad$ Mean post-cracking residual strength of SFRC

$f_{\text {su }} \quad$ Mean ultimate strength of reinforcing steel

$f_{\mathrm{y}} \quad$ Mean yielding strength of reinforcing steel

$f_{\mathrm{yk}} \quad$ Characteristic yielding strength of reinforcing steel

$f_{\mathrm{y}, \mathrm{sl}} \quad$ Mean yielding strength of longitudinal reinforcement

$f_{\mathrm{y}, \mathrm{st}} \quad$ Mean yielding strength of stirrups

$G_{\mathrm{cm}} \quad$ Mean shear modulus of concrete

$J_{\mathrm{t}} \quad$ Polar moment of inertia

$K \quad$ Torsional rigidity of the beam

$K_{\text {el }} \quad$ Initial torsional rigidity of the beam

$h \quad$ Height of the beam cross section

$p_{\mathrm{c}} \quad$ Outer perimeter of the cross section

$p_{\mathrm{o}} \quad$ Length of the mean-wall center line

$s_{\text {st }} \quad$ Stirrup spacing

$t_{\mathrm{c}} \quad$ Thickness of the equivalent thin-walled tube

$T_{\text {cr }} \quad$ Torque at first cracking

$T_{\mathrm{p}} \quad$ Torque at peak resistance

$T_{34} \quad$ Torque corresponding to a twist of $34 \times 10^{-3} \mathrm{rad} / \mathrm{m}$

$w_{\mathrm{m}} \quad$ Mean crack width

$\varepsilon_{\mathrm{su}} \quad$ Ultimate strain of reinforcing steel

$\theta \quad$ Inclination angle of the struts

$v \quad$ Poisson's coefficient

$\rho_{\mathrm{f}} \quad$ Volume fraction of steel fibers

$\rho_{1} \quad$ Longitudinal reinforcement ratio

$\rho_{\text {st }} \quad$ Transverse reinforcement ratio

$\rho_{\text {st,min }} \quad$ Minimum transverse reinforcement ratio according Eurocode 2

$\emptyset_{\text {st }} \quad$ Stirrup diameter

$\Psi \quad$ Twist

$\Psi_{\text {cr }} \quad$ Twist at first cracking

$\Psi_{\mathrm{p}} \quad$ Twist at peak resistance

\section{Introduction}

Reinforced Concrete (RC) structures in practice are rarely subjected to pure torsion. Typically, torsional moments are combined with a combination of bending moments, axial and/or shear forces. However, in order to gain a complete and comprehensive understanding of the phenomena governing the torsional behavior of $\mathrm{RC}$ members, the study of specimens subjected to pure torsion represents an important and unavoidable starting point. The latter becomes even more significant for practice when considering the high amount of transverse reinforcement required in beams subjected to low torsional moments.

The behavior of RC beams in pure torsion has been investigated for over a century. Following pioneering tests carried out by Mörsch [1] and Graf and Mörsch [2], many studies have been reported in the literature on the response of $\mathrm{RC}$ beams subjected to pure torsion, or in combination with other actions [3-9]. With the advent and increasing use of high-strength concretes in research and practice over the last two decades, tests on conventionally reinforced concretes with compressive strengths upward of $100 \mathrm{MPa}$ have been reported [10-12]. Furthermore, the response of RC beams strengthened with innovative materials and subjected to torsion have recently been reported [13-15]. All these tests confirm that, after first cracking, the shear stresses that develop as a result of the induced torsion are unable to be resisted unless a suitable mechanism is formed, which enables the transfer of stress across a cracked section. One such a mechanism can be described by the space truss analogy first developed by Rausch [16] and later refined by Lampert [17] and Lampert and Collins [18]. These models usually consist of diagonal compressive struts and tie elements (i.e., stirrups and rebars), which are formed to redress equilibrium and enable stresses to be transferred within the cracked sections [19].

As initially pointed out by Leonhardt and Mönning [20] and then recommended by different structural codes [21, 22], a minimum amount of longitudinal and transverse reinforcement must be provided in structural concrete in order to prevent brittle failure modes at the onset of first cracking. Considering that the role of web (transverse) reinforcement in members reinforced to resist torsion is analogous to that of stirrups in beams subjected to shear, the experimental results reported by Choi et al. [23], Susetyo et al. [24], Minelli and Plizzari [25] and Facconi and Minelli [26] appear to be very promising to support the view of partially or totally replacing of the minimum transverse reinforcement required to resist torsion by including steel fibers within the concrete matrix. The use of randomly orientated and uniformly distributed steel fibers in concrete improves its post-cracking behavior. This 
leads to tensile strengths and post-cracking toughness greater than those typically exhibited by Plain Concrete (PC) (i.e., concrete without fibers). Experimental tests performed worldwide over the last three decades have shown that fibers can be successfully used in different typologies to enhance the resistance of flexural- and shear-critical members such as beams [27-29], tunnels linings [30-32], slabs [33-35], etc. On the contrary, much less research on the topic of SFRC (Steel Fiber Reinforced Concrete) members subjected to torsion can be found in the literature.

The potential effectiveness of relying on steel fibers to resist torsion was first recognized by Mansur and Paramasivam [36] and shortly thereafter by Narayanan and Kareem-Palanjian [37, 38]. These studies reported an increase of the ultimate torsional strength, toughness and ductility of concrete beams subjected to pure torsion due to the inclusion of the fibers. Similar results were reported by Mansur et al. [39] after testing beams with different reinforcement ratios and steel fiber contents higher than $0.5 \%$ by volume, $\rho_{\mathrm{f}}$. Later, in 2003, those results were confirmed by Rao and Seshu [40], who observed a general improvement of the ultimate capacity, toughness and stiffness of beams subjected to pure torsion reinforced with fibers only. The authors concluded that a minimum fiber content of $0.9 \%$ is required to provide significant ductility to the torsional response. Chalioris and Karayannis [41] carried out 35 tests on rectangular and flanged beams containing both conventional reinforcement and relatively high contents of steel fibers $\left(\rho_{\mathrm{f}}=1 \%-3 \%\right)$. Aside of the typical observations noted above (i.e. increase of post-cracking torsional behavior due to fiber addition), Chalioris and Karayannis demonstrated that fibers have the potential to replace stirrups only if a very high volume fraction $\left(\rho_{\mathrm{f}}=3 \%\right)$ is supplied. Ultra-High Performance Fiber Reinforced Concrete (UHPFRC) beams subjected to pure torsion were tested by Yang et al. [42], who tested, among others, some beams without stirrups and characterized by varying longitudinal reinforcement ratios (i.e., $\left.\rho_{1}=0.56 \%, 0.88 \%, 1.27 \%\right)$ and high contents $\left(\rho_{\mathrm{f}-}\right.$ $=1 \%$ and $2 \%$ ) of high strength short steel fibers. In spite of the very high post-cracking strength and toughness exhibited by the uniaxial tensile constitutive laws for the different UHPFRCs adopted, all beams without stirrups were not able to increase the torsional strength after first cracking. However, as highlighted by other studies, a slight increase of the post-cracking resistance was generally observed for increasing values of longitudinal reinforcement ratio [43]. Amin and Bentz [44] recently carried out pure torsion tests on rectangular beams reinforced with $30 \mathrm{~kg} / \mathrm{m}^{3}$ of steel fibers $\left(\rho_{\mathrm{f}}=0.38 \%\right)$ combined with two different transverse reinforcement arrangements. The authors highlighted the ability of fibers to maintain the stress across cracks leading to an improved control of cover spalling.

The data inferred from the previous literature survey illustrates that a few studies were carried out on SFRC beams without stirrups and, moreover, most of those studies included specimens reinforced with fiber contents not lower than $0.6 \%$. Such dosages of steel fibers may be economically deterring in practice.

In addition, several experimental tests have been performed on beams without longitudinal reinforcement; the consequence of which is that the well-known space truss torsional resisting mechanism cannot be fully established. Furthermore, specimens without longitudinal reinforcement are not representative of members constructed in practice.

Moreover, except for a few recently published studies, many research programs have not reported a complete mechanical characterization of the postcracking tensile behavior of SFRC at the material level. Most of these studies generally provide an assessment of the tensile strength of the concrete matrix only, without any consideration for the residual tensile strength provided by the fibers for a particular SFRC rheology. Without this information, consideration on the torsional response of beams composed of SFRC cannot be fully exhaustive.

To bridge this lack of information, this paper presents a series of pure torsion tests on SFRC beams with longitudinal reinforcement and without stirrups alongside a full suite of material characterization tests. The two pairs of beams were supplied with the same longitudinal reinforcement $\left(\rho_{1}=1.13 \%\right)$ and two different dosages of steel fibers respectively equal to $25 \mathrm{~kg} / \mathrm{m}^{3}\left(\rho_{\mathrm{f}}=0.32 \%\right)$ and $50 \mathrm{~kg} / \mathrm{m}^{3}\left(\rho_{\mathrm{f}}=0.63 \%\right)$. Companion notched beams for characterizing the tensile post-cracking behavior of SFRC were cast and tested under three-point bending. In order to assess the suitability of SFRC beams without stirrups to replace minimum transverse reinforcement requirements, a control test was also performed on a conventional $\mathrm{RC}$ beam containing the minimum torsional reinforcement recommended by Eurocode 2 
[21]. Finally, a RC beam without stirrups was also tested as a reference sample.

The main results of the tests will be presented and discussed, by including considerations on the torsional rigidity, the deformation energy and the evolution of the crack pattern. A comparison with other results found in the literature will be also reported and discussed.

\section{Experimental program}

\subsection{Test specimens}

An experimental investigation was carried out on a total of six PC and SFRC beams subjected to pure torsion. All members were geometrically identical with an overall length of $2700 \mathrm{~mm}$ and a cross-section of $300 \times 300 \mathrm{~mm}$, typical of edge beams in reinforced concrete buildings. The specimens contained
$18 \mathrm{~mm}$ diameter $(\varnothing 18)$ longitudinal deformed steel rebars located in each corner of the cross section. The longitudinal reinforcement was chosen to ensure its elastic response during the application of the torque. The specimen geometry and reinforcement detailing are illustrated in Fig. 1. Details of each specimen tested in this study are presented in Table 1. TB1-PC was a plain concrete (PC) beam and did not contain any transverse reinforcement. TB2-PC-ST was also a plain concrete specimen and contained $6 \mathrm{~mm}$ diameter deformed steel stirrups $\left(\emptyset_{\mathrm{st}}\right)$ spaced at $110 \mathrm{~mm}\left(\mathrm{~s}_{\mathrm{st}}\right)$ centers. Two identical SFRC beams (TB3-SFRC25, TB4-SFRC25) were reinforced with $25 \mathrm{~kg} / \mathrm{m}^{3}$ of steel fibers and, lastly, other two identical SFRC beams (TB5-SFRC50, TB6-SFRC50) contained $50 \mathrm{~kg} / \mathrm{m}^{3}$ of steel fibers. The hooked-end steel fibers used in this study were $30 \mathrm{~mm}$ long, had a diameter of $0.35 \mathrm{~mm}$ and a tensile strength of $2200 \mathrm{MPa}$. No transverse steel reinforcement was placed in the SFRC members. The transverse reinforcement arrangement of TB2-

\section{TB2-PC-ST beam}

$\underline{\text { Section A-A }}$
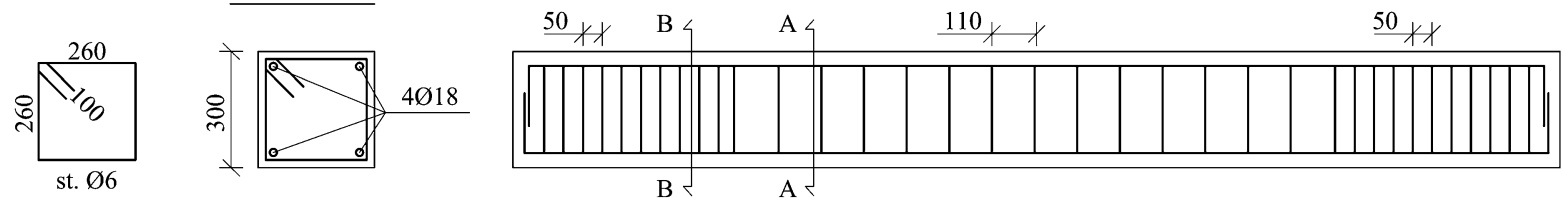

$\underline{\text { Section B-B }}$
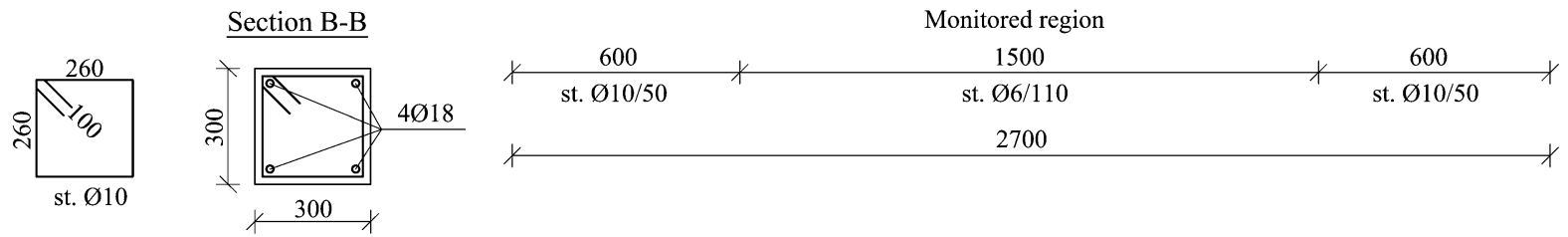

\section{TB1-PC \& SFRC beams}

$\underline{\text { Section A-A }}$
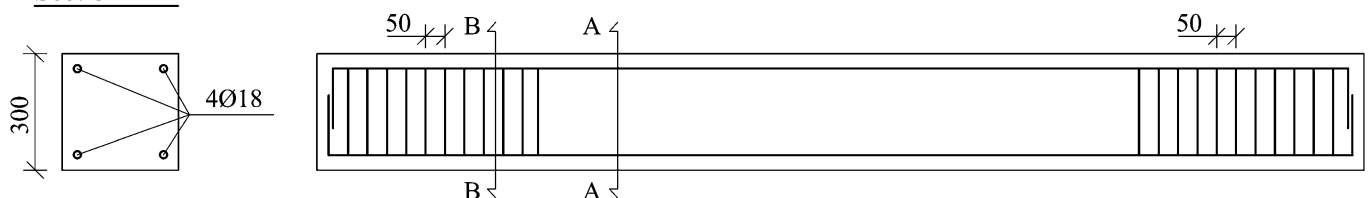

Section B-B
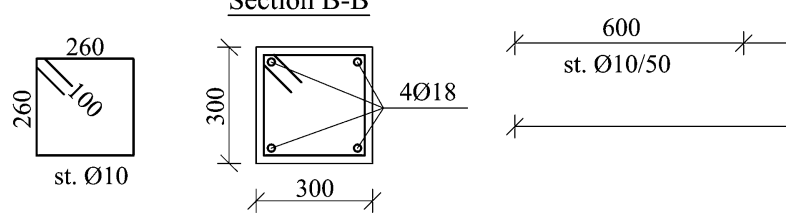

Monitored region

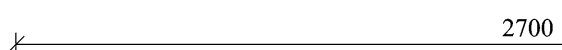

Fig. 1 Geometry and reinforcement details of the test specimens (dimensions in $\mathrm{mm}$ )

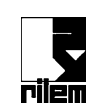


Table 1 Main properties of beam specimens

\begin{tabular}{lllllll}
\hline Specimen & Material ID & $\rho_{\mathrm{l}}(\%)$ & Stirrups $\emptyset_{\mathrm{st}} / \mathrm{s}_{\mathrm{st}}(-)$ & $\rho_{\mathrm{st}}(\%)$ & Fiber content $\left(\mathrm{kg} / \mathrm{m}^{3}\right)$ & $\rho_{\mathrm{f}}(\%)$ \\
\hline TB1-PC & PC & 1.13 & - & - & - & - \\
TB2-PC-ST & PC & 1.13 & $6 / 110$ & 0.17 & - & - \\
TB3-SFRC25 & SFRC25 & 1.13 & - & - & 25 & 0.32 \\
TB4-SFRC25 & SFRC25 & 1.13 & - & - & 25 & 0.32 \\
TB5-SFRC50 & SFRC50 & 1.13 & - & - & 50 & 0.63 \\
TB6-SFRC50 & SFRC50 & 1.13 & - & - & 50 & 0.63 \\
\hline
\end{tabular}

PC-ST fulfilled the following minimum requirements recommended by Eurocode 2 [21] (clause 9.2.3):

$\rho_{\mathrm{st}}=\frac{A_{\mathrm{sw}}}{s_{\mathrm{st}} \cdot b}=0.17 \% \geq \rho_{\mathrm{st}, \text { min }}=0.08 \cdot \frac{\sqrt{f_{\mathrm{ck}}}}{f_{\mathrm{yk}}}=0.1 \%$

$s_{\mathrm{st}}=110 \mathrm{~mm} \leq \min \left(p_{\mathrm{c}} / 8,0.75 d\right)$

$=150 \mathrm{~mm} \& \min (b, h)=300 \mathrm{~mm}$

where $\rho_{\mathrm{st}}$ and $\rho_{\mathrm{st}, \min }$ are the actual and the minimum required transverse reinforcement ratios, respectively. In Eq. $1, f_{\mathrm{ck}}=31.7 \mathrm{MPa}$ is the cylindrical characteristic compressive strength of the concrete used to manufacture the beam TB2-PC-ST; $f_{\mathrm{yk}}=450 \mathrm{MPa}$ is the characteristic yielding strength of stirrups $\varnothing 6$. In Eq. $2, \mathrm{~b}=\mathrm{h}=300 \mathrm{~mm}$ are the width and the height of the cross section, respectively; $p_{\mathrm{c}}=1200 \mathrm{~mm}$ is the perimeter of the cross section; $A_{\mathrm{sw}}=56.5 \mathrm{~mm}^{2}$ is the total area of transverse reinforcement; $\mathrm{s}_{\mathrm{st}}=110 \mathrm{~mm}$ is the spacing of stirrups; and $\mathrm{d}=265 \mathrm{~mm}$ is the effective depth of the section.

Table 1 summarizes the basic properties of the specimens such as the longitudinal $\left(\rho_{1}=A_{\mathrm{sl}} / A_{\mathrm{c}}\right)$ and transverse $\left(\rho_{\mathrm{st}}\right)$ reinforcement ratios as well as the fiber volume fraction $\left(\rho_{\mathrm{f}}\right)$. Note that $A_{\mathrm{c}}=9 \times 10^{4} \mathrm{~mm}^{2}$ is the area of the beam gross section.

All beams consisted of a monitored region, in which pure torsion was assumed to be completely developed, and two disturbed regions located at both ends of the member (refer to Fig. 1). To prevent torsional failure as well as local damages due to stress concentrations and to promote the full development of torsion in the middle portion of the beam (i.e., within the monitored region), the outer disturbed regions were provided with closely spaced (spacing $=50 \mathrm{~mm}) 10 \mathrm{~mm}$ diameter stirrups.

\section{Materials}

The concrete mix-design reported in Table 2 was adopted for all test specimens. After casting, the beams were stacked on the laboratory floor at room temperature up to the time of testing. To reduce the likelihood of any cracking due to shrinkage occurring, each specimen was covered with a polyethylene sheet and kept within the timber molds for at least 7 days after casting.

The average value of the fresh and hardened mechanical properties of the three concrete mixes and the corresponding coefficient of variation (percentage values within round brackets) are presented in Table 3. The consistency of fresh concrete was measured by a slump test (i.e., Abrams cone) according to EN 12350-2 [45]. Based on the results of the slump test, the slump classes (EN 206-1 (2006) [46]) reported in Table 3 show that the slump of the two SFRCs ranged between 160 and $200 \mathrm{~mm}$ (class S4) whereas PC showed a slump of $145 \mathrm{~mm}$ (class S3). This is due to the increase in superplasticizer supplied for the SFRC mixes. The mean uniaxial compressive strength $\left(\mathrm{f}_{\mathrm{cm} \text {,cube }}\right)$ of the mixes was assessed by testing $150 \mathrm{~mm}$ cubes after at least 28 days curing in a controlled environmental chamber having a constant temperature of $20^{\circ} \mathrm{C}$ and relative humidity of about 95\%. The cylindrical mean compressive strength $\left(f_{\mathrm{cm}}\right)$ was calculated as $0.83 \cdot f_{\text {cm,cube }}$. The mean tensile strength $\left(f_{\text {ctm }}\right)$ and the mean secant elastic modulus $\left(E_{\mathrm{cm}}\right)$ of the concretes were both calculated according Eurocode 2 [21] as $f_{\mathrm{ctm}}=0.3 \mathrm{f}_{\mathrm{ck}}{ }^{2 / 3}$ and $E_{\mathrm{cm}}=22 \cdot\left(f_{\mathrm{cm}} /\right.$ $10)^{0.3}$.

The fracture behavior of each mix was characterized by performing a series of 3-point bending tests (3PBTs) on $150 \times 150 \times 500 \mathrm{~mm}^{3}$ notched prisms tested in accordance to EN 14651 [47]. The tests 
Table 2 Concrete composition and properties of steel fibers
Table 3 Concrete properties
*Calculated according Eurocode 2 [21]

**FRC classification according $f i b$ Model Code 2010 [48]

(CV\%) Coefficient of Variation reported into round brackets

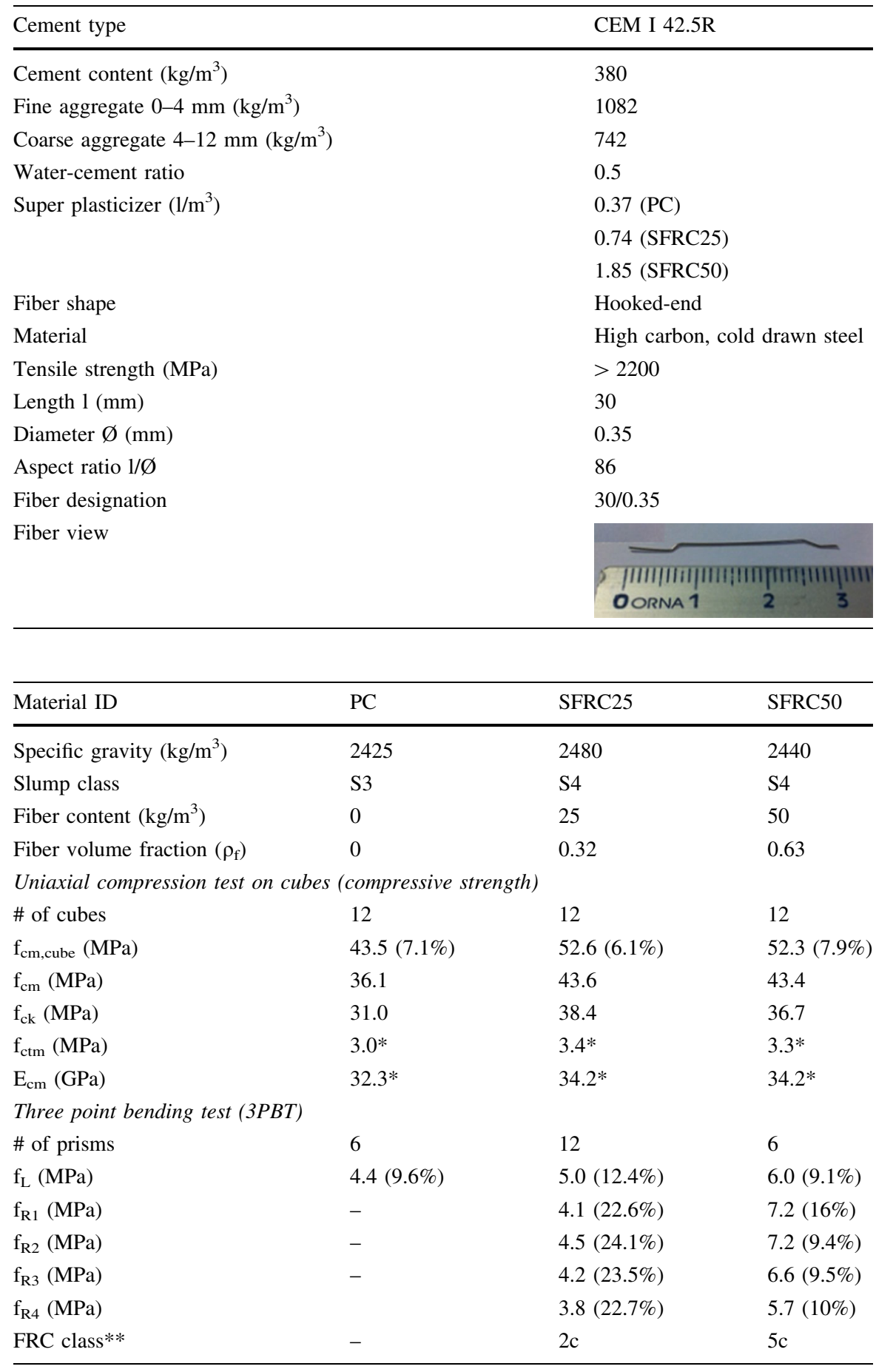

provided the flexural tensile stress-CMOD (Crack Mouth Opening Displacement) curves depicted in Fig. 2, which allows determining the residual strength parameters required by the $f i b$ Model Code 2010
(MC2010) [48] to characterize the post-cracking behavior of SFRC. As summarized in Table 3, the aforementioned residual strength parameters include the limit of proportionality $f_{\mathrm{L}}$ (i.e. the highest flexural 


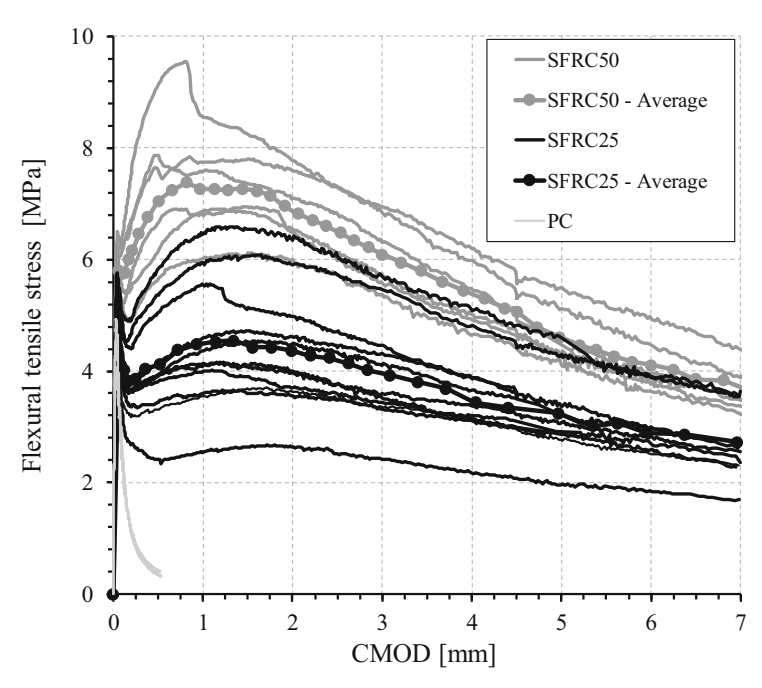

Fig. 2 Flexural tensile stress-CMOD curves from three point bending tests according EN 14651 [47]

tensile strength detected for CMOD ranging from 0 to $0.05 \mathrm{~mm})$ and the residual strengths $\mathrm{f}_{\mathrm{R}, 1}(\mathrm{CMOD}=$ $0.5 \mathrm{~mm}), f_{\mathrm{R}, 2}(\mathrm{CMOD}=1.5 \mathrm{~mm}), f_{\mathrm{R}, 3}(\mathrm{CMOD}=$ $2.5 \mathrm{~mm})$, and $f_{\mathrm{R}, 4}(\mathrm{CMOD}=3.5 \mathrm{~mm})$.

The comparison between the PC and the SFRC curves of Fig. 2 shows, as expected, that the addition of fibers drastically increased the post-cracking strength and toughness of the concrete. It is seen that, considering the CMOD values ranging from 0.5 to $3.5 \mathrm{~mm}$, the residual strengths for mix SFRC50 were $50-75 \%$ higher than those presented for mix SFRC25. Since short fibers (fiber length $<40 \mathrm{~mm}$ ) were used, the maximum performance in tension of both SFRC materials was observed right after the localization of the crack in the notched section, when the CMOD was lower than $2 \mathrm{~mm}$. Note the scatter in the post-cracking range of the results, particularly for mix SFRC25.

Both the stirrups and the longitudinal reinforcement were composed of conventional steel deformed bars (B450 C according to Eurocode 2 [21]) having the mechanical properties reported in Table 4. The latter were obtained by testing four samples for each bar typology according to the testing procedure described by ISO 15630-1[49].

\subsection{Test set-up and instrumentation}

A state of pure torsion was applied to the specimens using the test rig illustrated in Fig. 3a. The specimens were supported at both ends by steel rollers that allowed free rotation about the longitudinal axis of the beam, without preventing extension or contraction due to deformation induced by the applied torsion. Each roller was aligned to the beam axis and welded to a bottom steel plate (plate (A) -Fig. 3a). A different steel plate (plate (B)-Fig. 3a) was laid on the roller to provide support to the bottom surface of the specimen. Four bolts were used to connect plate (B) to the steel cantilever placed on the top side of the specimen. The beam-to-plate (B) and the beam-to-steel cantilever interfaces were both filled with a thin layer of shrinkage compensating mortar to prevent contact problems pertaining to any possible uneven surfaces and to make specimen levelling operations much easier. Two equal counteracting torques were applied to the test beam by means of the steel cantilevers loaded by the spreader beam placed diagonally with respect to the longitudinal axis of the specimen. A stiff spreader beam was used to equally distribute the total vertical load (P) from the actuator to the two cantilevered ends, which provided the torsion arm (564 mm-see Fig. 3) of the twisting moment. The total load $(\mathrm{P})$ acting on the center of the spreader beam was applied by the transversal loading beam which, in turn, was loaded by a couple of vertical Dywidag bars connected to a $1000 \mathrm{kN}$ capacity electromechanical thrust jack. To continuously monitor the total load, two load cells were clamped between the Dywidag bars and the loading beam. Figure $3 b$ shows the

Table 4 Properties of steel deformed rebars

\begin{tabular}{lclll}
\hline Reinforcing bar type & Diameter $(\mathrm{mm})$ & $f_{\mathrm{y}}(\mathrm{MPa})$ & $f_{\text {su }}(\mathrm{MPa})$ & $\varepsilon_{\mathrm{su}}(\%)$ \\
\hline$\varnothing 6$ & 6 & $485(1.9 \%)$ & $597(0.42 \%)$ & $15.6(14 \%)$ \\
$\varnothing 10$ & 10 & $524(2.1 \%)$ & $660(1.5 \%)$ & $12.6(10 \%)$ \\
$\varnothing 18$ & 18 & $516(2.0 \%)$ & $659(2.7 \%)$ & $17.7(11 \%)$ \\
\hline
\end{tabular}

(CV\%) Coefficient of variation reported into round brackets 


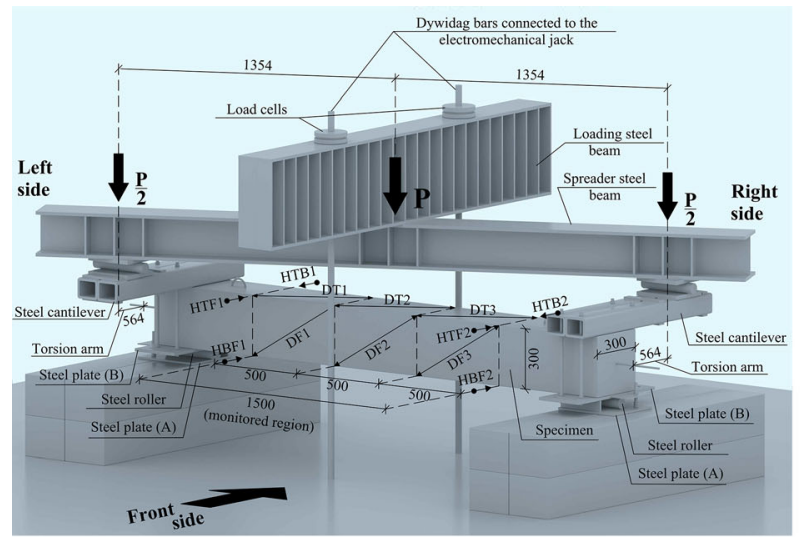

(a)

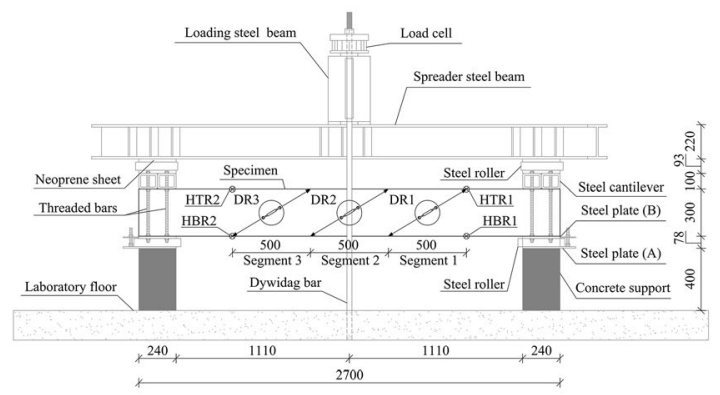

(b)

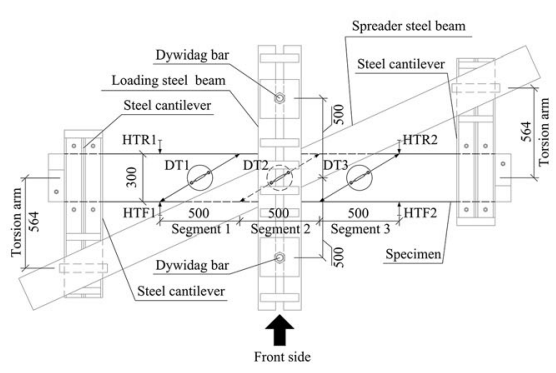

(c)

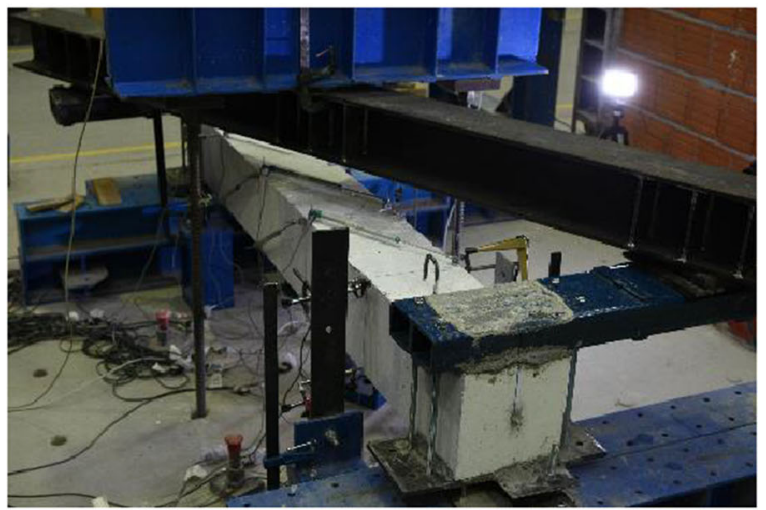

(d)

Fig. 3. Test set-up: 3D schematic view (a); top-view (b) and rear-view (c) schematics; actual view (d) (dimensions in mm)

specimen TB3-SFRC25 prior to the application of load.

As shown in Fig. 3a, two potentiometers were located at each end of the monitored region in order to detect the horizontal displacement resulting from the rotation of the beam about its longitudinal axis. The following 4-index notation was used for labelling each horizontal sensor: first index, $\mathrm{H}$ for horizontal; second index, $\mathrm{T}$ for top side and $\mathrm{B}$ for bottom side of the beam; third index, $\mathrm{F}$ for front and $\mathrm{R}$ for rear side of the beam; the fourth digit refers to either the left (1) or the right (2) end section of the monitored region. To detect the potential growth of cracks, which were expected to have an inclination to the longitudinal axis of the specimens ranging from $30^{\circ}$ to $50^{\circ}$, three potentiometers were installed on each of the four sides of the beam. A similar notation was chosen for these 12 sensors: first index, D for diagonal instrument; second index, T, R, F, B for top, rear, front and bottom side, respectively; the third index is used to number each of the three potentiometers, starting from the left side of the beam (Fig. 3a).

The load was monotonically increased at a constant speed so that the rate of change of the unit angle of twist of the beam was about $0.01 \mathrm{rad} /(\mathrm{m} \mathrm{s})$. This type of displacement control performed by the electromechanical actuator allowed to carefully control the postpeak softening response of the test beams. Data was detected and stored by a data acquisition system at constant intervals of $0.5 \mathrm{~s}$.

\section{Experimental results and discussion}

Figure 4 and Table 5 present the Torque (T) versus twist $(\Psi)$ response of each of the specimens and the key results of the tests, respectively. In Table $5, \mathrm{~K}_{\mathrm{el}, \exp }$ is the initial torsional rigidity, $\mathrm{T}_{\mathrm{cr}}$ and $\Psi_{\mathrm{cr}}$ are the torque and the corresponding twist at first cracking, respectively and $\mathrm{T}_{\mathrm{p}}$ and $\Psi_{\mathrm{p}}$ are the torque and the corresponding twist at peak load. Moreover, for each 


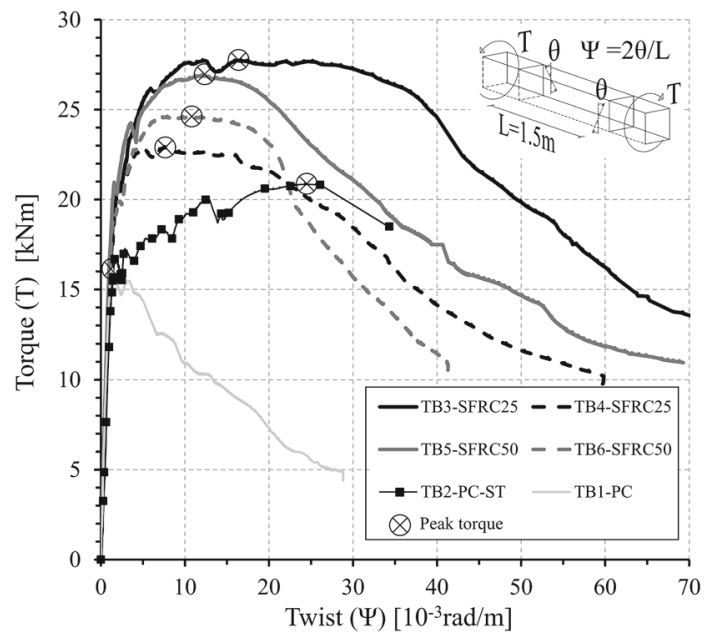

(a)

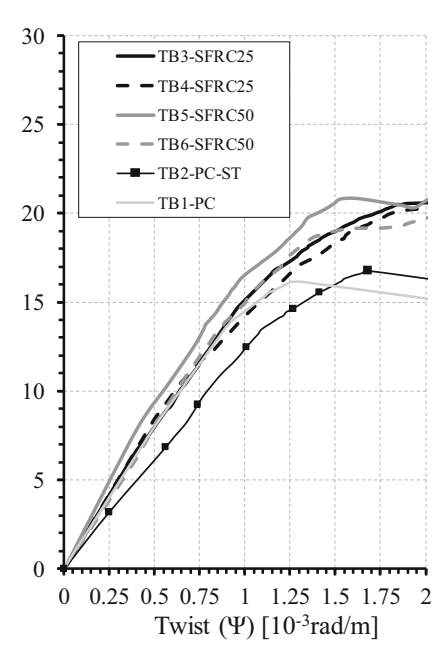

(b)

Fig. 4 Torque versus twist experimental curves: overall response (a); focus on the initial branch (b)

Table 5 Summary of main experimental results

\begin{tabular}{lllllcrc}
\hline Specimen & $\mathrm{K}_{\text {el,exp }}\left(\frac{\mathrm{kNm}^{2}}{\mathrm{rad}}\right)$ & $\mathrm{T}_{\text {cr }}(\mathrm{kNm})$ & $\Psi_{\mathrm{cr}}\left(\frac{10^{-3} \cdot \mathrm{rad}}{\mathrm{m}}\right)$ & $\mathrm{T}_{\mathrm{p}}(\mathrm{kNm})$ & $\Psi_{\mathrm{p}}\left(\frac{10^{-3} \cdot \mathrm{rad}}{\mathrm{m}}\right)$ & $\Psi_{\mathrm{p}} / \Psi_{\text {cr }}(-)$ & $\mathrm{T}_{34}(\mathrm{kNm})$ \\
\hline TB1-PC & 15,900 & 12.40 & 0.78 & 16.18 & 1.25 & 1.7 & - \\
TB2-PC-ST & 12,850 & 13.08 & 1.06 & 20.84 & 24.35 & 23.0 & 18.53 \\
TB3-SFRC25 & 16,700 & 13.40 & 0.88 & 27.32 & 15.38 & 14.1 & 26.58 \\
TB4-SFRC25 & 17,100 & 12.00 & 0.80 & 22.94 & 7.52 & 9.4 & 16.82 \\
TB5-SFRC50 & 19,630 & 13.89 & 0.79 & 26.94 & 12.00 & 15.2 & 19.28 \\
TB6-SFRC50 & 15,400 & 13.74 & 1.17 & 24.63 & 10.52 & 9.0 & 13.93 \\
\hline
\end{tabular}

of the test beams, Table 5 reports the torque $\left(\mathrm{T}_{34}\right)$ corresponding to the maximum twist (i.e., $\Psi=34$ $\times 10^{-3} \mathrm{rad} / \mathrm{m}$ ) achieved by specimen TB2-PC-ST at the conclusion of testing. It is worth remarking that the twist is here calculated as the ratio between the angle of rotations $\theta$ (i.e., the sum of the angles of rotation detected at both ends of the monitored region) and the length $(\mathrm{L}=1.5 \mathrm{~m})$ of the monitored region.

\subsection{Overall torsional behavior of the specimens}

Figure 4a compares the overall torsional response of the six specimens. The initial elastic branches of all curves presented in Fig. 4b displayed similar rigidities and consistent values for the torque and twist at first cracking. This is to be expected, as the contribution of fibers to concrete at the material constitutive level has minimal influence to the response prior to cracking. Only the beams TB2-PC-ST and TB5-SFRC50 presented a slightly different stiffness as compared to the other specimens. Averaging the data reported in Table 5, the mean torque and twist at first cracking results in $13.1 \mathrm{kNm}$ and $0.9 \times 10^{-3} \mathrm{rad} / \mathrm{m}$, with a CV of $6 \%$ and $18 \%$, respectively.

Cracking occurs when the maximum tensile stress due to torsion reaches the tensile strength of concrete. Different equations have been proposed to estimate the torque corresponding to first cracking. For instance, according to the classical de Saint-Venant's (DSV) theory, the first cracking torque ( $\mathrm{T}_{\text {cr,DSV }}$ ) of a rectangular section results from the following equation: 
$T_{\mathrm{cr}, \mathrm{DSV}}=f_{\mathrm{ctm}} \cdot \frac{b \cdot h^{2}}{3+1.8 h / b}=16.88-19.13 \mathrm{kNm}$

where the minimum and maximum value of the torque have been calculated by considering respectively the lowest and the highest value of concrete tensile strength $\left(f_{c t m}\right)$ reported in Table 3 . Based on the "thin-walled tube theory" (WTT), as also reported in Collins and Mitchell [50], the cracking torque $\left(\mathrm{T}_{\mathrm{cr}, \mathrm{WTT}}\right)$ can be calculated as follows:

$T_{\mathrm{cr}, \mathrm{WTT}}=0.33 \sqrt{f_{\mathrm{cm}}} \cdot \frac{A_{c}^{2}}{p_{\mathrm{c}}}=13.38-14.70 \mathrm{kNm}$

The two extreme values of the resisting torque presented in Eq. 4 are related to the minimum and the maximum value of the measured $\mathrm{f}_{\mathrm{cm}}$ (Table 3 ). Note that both the Eqs. 3 and 4 depend, directly or indirectly, on the tensile strength of concrete, whose value is independent of the fiber dosage. The average cracking torque provided by the present tests is very close to the one predicted by WTT and, at the same time, is more than $20 \%$ lower than the torque predicted by the de Saint Venant's expression. However, considering several factors (e.g., pre-existing shrinkage tensile strains, variability of concrete tensile strength) that may affect the prediction of first cracking resistance of the member, the experimental values of $\mathrm{T}_{\mathrm{cr}}$ observed herein appear very reasonable.

As expected, at first cracking, the beam without fibers and stirrups (TB1-PC) achieved its maximum torque $\left(\mathrm{T}_{\mathrm{p}}=16.18 \mathrm{kNm}\right)$. After that, it started exhibiting a consistent softening response clearly governed by the post-cracking tensile behavior of PC. On the contrary, all the other specimens showed the ability to withstand increasing loads after first cracking because of the increased post-cracking tensile resistance provided by either the transverse reinforcement or steel fibers.

Regarding specimen TB2-PC-ST, the torque-twist response after cracking $\left(>1.67 \times 10^{-3} \mathrm{rad} / \mathrm{m}\right)$ reveals a sudden loss in stiffness which corresponded to a sudden increase of twist, typical of conventionally RC beams [19]. At this stage of testing, the ability of the beam to resist the applied load is closely related to the activation of the space truss mechanism, in which diagonal concrete compressive strains and steel tensile strains acting in the longitudinal and transverse rebars determine the twist angle. Since longitudinal rebars were designed to remain elastic for all test specimens, the maximum torque $\left(T_{\mathrm{p}}=20.84 \mathrm{kNm}\right)$ was considerably lower than that corresponding to yielding of longitudinal rebars. Therefore, failure was governed by yielding of transverse rebars. For safety reasons, the test was terminated after the first sharp reduction of torsional resistance during the post-peak response (i.e. prior to rupture of the transverse reinforcement).

The significant loss of torsional rigidity, which characterized the response of the beam TB2-PC-ST after cracking, was not observed for the four SFRC beams, whose post-cracking response was considerably much stiffer. As shown in Fig. 4, the applied torque continued to increase until the maximum capacity was reached. The latter ranged from a minimum of $22.94 \mathrm{kNm}$ to a maximum $27.32 \mathrm{kNm}$, which were respectively $10 \%$ and $31 \%$ higher than the peak resistance of the beam TB2-PC-ST. Moreover, the angle $\Psi_{\mathrm{p}}$ of the SFRC beams was always more than $50 \%$ lower than that observed for the beam TB2-PC-ST. After the attainment of the maximum torque, an almost horizontal plateau followed by a descending branch was observed in all beams. It is worth noting that, irrespective of the adopted fiber content, steel fibers appeared to be effective in providing an overall stable and ductile response because of their ability to control the progression of cracking. Both the horizontal plateau and the gradual post-peak softening response described above represent clear evidence of the stability that characterizes the overall response of SFRC beams. As shown by the scatter of values corresponding to the torque $T_{34}$ (Table 5), the descending branches exhibited by the SFRC beams after the plateau were considerably different in term of resisting torque and rotational capacity. As a matter of fact, the torque $T_{34}$ achieved by the specimen TB3-SFRC25 was about 90\% higher than that of the beam TB6-SFRC50.

\subsection{Torsional rigidity}

Table 5 indicates that the initial torsional rigidity $\left(\mathrm{K}_{\mathrm{el}, \mathrm{exp}}\right)$ varied from $12,850 \mathrm{kNm}^{2} / \mathrm{rad}$ (TB2-PC-ST) to 19,630 $\mathrm{kNm}^{2} / \mathrm{rad}$ (TB5-SFRC50), with an average of $16,263 \mathrm{kNm}^{2} / \mathrm{rad}$ and a CV of about $14 \%$. Using the polar moment of inertia $\left(J_{\mathrm{t}}=b h^{3} /\left[3+4.1(h / b)^{3 / 2}\right]\right)$ of the cross section, the DSV theory defines elastic rigidity as follows: 
$K_{\mathrm{DSV}}=G_{\mathrm{cm}} \cdot J_{\mathrm{t}}=15,830 \mathrm{kNm}^{2} / \mathrm{rad}$

where $G_{\mathrm{cm}}=E_{\mathrm{cm}} /[2(1+v)]=13.9 \mathrm{GPa}$ is the shear modulus of concrete; $v=0.2$ is the Poisson's coefficient; $E_{\mathrm{cm}}=33.3 \mathrm{GPa}$ is obtained by averaging the elastic moduli of concrete reported in Table 3; $J_{\mathrm{t}}=1.141 \times 10^{9} \mathrm{~mm}^{4}$. The rigidity provided by Eq. 5 is only $3 \%$ lower than the average value of $K_{\text {el,exp }}$ but, on the contrary, it is $23 \%$ higher and $19 \%$ lower respectively than the minimum and maximum rigidity exhibited by SFRC specimens. However, considering the uncertainties that typically affect experimental results, one may conclude that the torsional rigidity experimentally observed is well predicted by the classical DSV theory.

As observed above, the SFRC specimens were not affected by the sharp reduction of the torsional stiffness presented by the specimen TB2-PC-ST at the onset of cracking (Fig. 4). To better estimate the actual improvement provided by fibers, the secant torsional rigidity $(\mathrm{K})$ of the test beams was plotted against the normalized twist $\left(\Psi / \Psi_{\mathrm{cr}}\right)$. These results are presented in Fig. 5. Based on a similar approach used by Mc Mullen and El-Degwy [51] to define the cracked stiffness, the secant rigidity (Fig. 5) was calculated as the slope (i.e., $\left.\left(T_{2}-T_{1}\right) /\left(\Psi_{2}-\Psi_{1}\right)\right)$ of the line corresponding to a given range of twist values, whereas the normalized twist was defined as the actual twist $(\Psi)$ to the first cracking twist $\left(\Psi_{\mathrm{cr}}\right)$ ratio. For example, $\Psi / \Psi_{\mathrm{cr}}=1$ at first cracking. For each beam, only a few ranges of values for the normalized twist

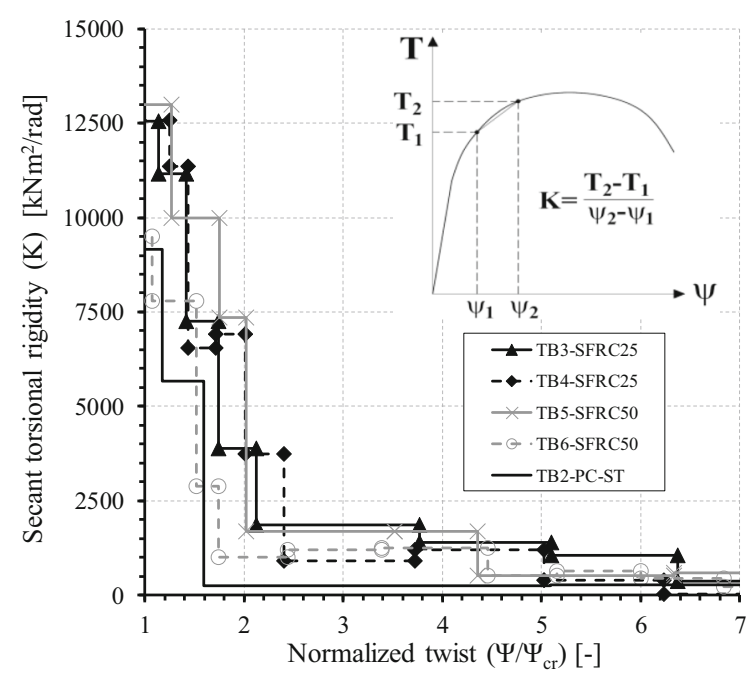

Fig. 5 Secant torsional rigidity versus normalized twist were considered to estimate the rigidity. Each range was selected such that the secant line reasonably approximated the average slope of the torque-twist curve without considering local disturbances of the experimental curve. This simplification made the comparison of the five specimens much clearer.

The curves of Fig. 5 allow appreciating the significant reduction of torsional stiffness that affected specimen TB2-PC-ST after cracking. In fact, once the normalized twist reached a value of 1.6, the stiffness of the beam TB2-PC-ST dropped to $260 \mathrm{kNm}^{2} / \mathrm{rad}$ and then remained approximately constant up to the peak torsional resistance. Except for beam TB6-SFRC50, whose loss of rigidity within the normalized twist range 1-1.6 was as fast as that of TB2-PC-ST, all the other SFRC samples showed a more gradual reduction of rigidity, which however remained always higher than that of TB2-PC-ST. The highest decrement of rigidity after cracking occurred within the normalized twist range 1-2.4. After that, the SFRC beams presented almost constant rigidities that were 3.7-7.4 times higher than the minimum $\left(260 \mathrm{kNm}^{2} / \mathrm{rad}\right)$ exhibited by TB2-PC-ST. It is noteworthy that for normalized twists falling in the range 2.2-4.2, the rigidities of the SFRC beams varied from $915 \mathrm{kNm}^{2} / \mathrm{rad}$ (TB4-SFRC25) to a maximum of $1850 \mathrm{kNm}^{2} / \mathrm{rad}$ (TB3-SFRC25). Normalized twists higher than 4.2 led to a steady decrement of rigidity of the SFRC specimens that tended to approach the TB2PC-ST curve. All the torsional rigidities became negligible once the normalized twist was over a value of 7 .

\subsection{Strain energy}

The strain energy of each specimen was calculated by integrating the area bounded by the horizontal axis and the corresponding torque-twist curve shown in Fig. 4. The evolution of the cumulated energy is plotted in Fig. 6 as a function of the twist. As one may observe, the cumulated energy of all the SFRC beams is always greater than that exhibited by the specimen TB2-PCST.

Considering a twist of $34 \cdot 10^{-3} \mathrm{rad} / \mathrm{m}$, which corresponded to the maximum rotation achieved by the beam TB2-PC-ST, the total energy absorption of the SFRC members ranged from $1055 \mathrm{~kJ} \cdot \mathrm{rad}$ (TB4SFRC25) to $1218 \mathrm{~kJ} \cdot \mathrm{rad}$ (TB5-SFRC50). On the contrary, the maximum energy absorption of the beam TB2-PC-ST (977 kJ.rad) was $7 \%$ and $20 \%$ lower than the former ones, respectively. These results indicate 


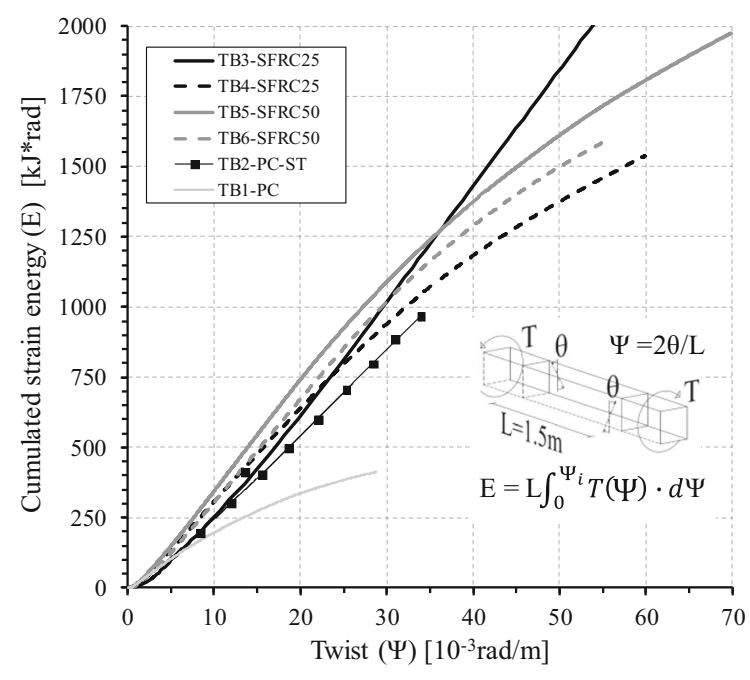

Fig. 6 Cumulated strain energy versus twist

that substituting stirrups for fibres can improve the performance of the beams both in terms of ultimate resistance and rotational capacity, leading to a higher energy absorption.

As expected, among the SFRC specimens, the TB3SFRC25 and the TB4-SFRC25 recorded the highest and the lowest energy absorbing capacity, respectively.

\subsection{Cracking evolution}

Prior to testing, a careful examination of each surface of each beam was performed using a handheld digital microscope to determine whether any significant cracks due to shrinkage developed between casting and testing. No crack was detected with this regard.

During testing, the crack patterns were continuously monitored and manually recorded. The crack patterns detected at the end of the tests are presented in Fig. 7. For the purpose of reporting, the monitored region was divided into 3 segments of equal length (i.e., $500 \mathrm{~mm}$ ). These are denoted as Segment 1, Segment 2 and Segment 3, as shown in Fig. 7.

The crack pattern of the beam TB1-PC consisted of a main localized crack, having an inclination of about $40^{\circ}-58^{\circ}$. This main crack began to localize within Segments 1 and 2 (see Fig. 3) at the onset of first cracking. As it is typical of PC, the main and the few secondary cracks rapidly propagated as the twist gradually increased. The brittle collapse of the beam was prevented by the displacement-controlled testing procedure.
Owing to its transverse reinforcement, TB2-PC-ST exhibited several cracks especially within Segments 2 and 3. At first cracking, few cracks started to form in the Segment 2. With increasing load, more cracks developed and each of these cracks subsequently widened. After peak load was attained, significant spalling of concrete cover was observed in an area between the rear and the bottom side of the beam (see Segment 2 in Fig. 3). The slope of the cracks detected after failure ranged from $30^{\circ}$ to $51^{\circ}$.

In terms of damage evolution, the behavior of the four SFRC specimens was quite similar. More specifically the main cracks appeared on the surface of the beam before the onset of the post-peak descending branch of the torque vs. twist response (Fig. 4). As the torque decreased after the peak, the damage gradually localized in a single crack, whose width continued to increase till the end of the test. This was with exception for beam TB3-SFRC25, in which two major cracks developed and steadily progressed in width up to significant values, leading to a higher overall capacity. In addition, the crack pattern of the beam TB5-SFRC50 showed slightly more diffused cracks than in the specimen TB6-SFRC50. Note that crack inclination of the SFRC beams fell in the range $38^{\circ}$ $50^{\circ}$, with a maximum slope of $60^{\circ}-67^{\circ}$ detected for very few cracks.

When the quasi-horizontal branch of the torquetwist response was attained, the crack pattern of the SFRC beams tended to stabilize and, therefore, the number of primary cracks remained almost constant up to the end of the test. Similar to the SFRC beams, the crack pattern of TB2-PC-ST remained stable as the torque decreased after the peak. In view of this, the mean crack width $\left(\mathrm{w}_{\mathrm{m}}\right)$ can be reasonably estimated by dividing the elongation of each diagonal potentiometer (see par. 2.3 and Fig. 3) by the number of cracks spanned by the instrument. The obtained width is an approximation of the actual value, as the potentiometers were not generally perpendicular to the direction of cracks. In view of future developments of analytical models able to accurately predict the torsional resistance of FRC members, a good estimation of the expected average crack width at peak torque for the dominant crack would be of paramount importance.

A summary of the crack widths detected in each segment and side of the specimens is reported in Table 6 . The rows and columns of Table 6, named as 

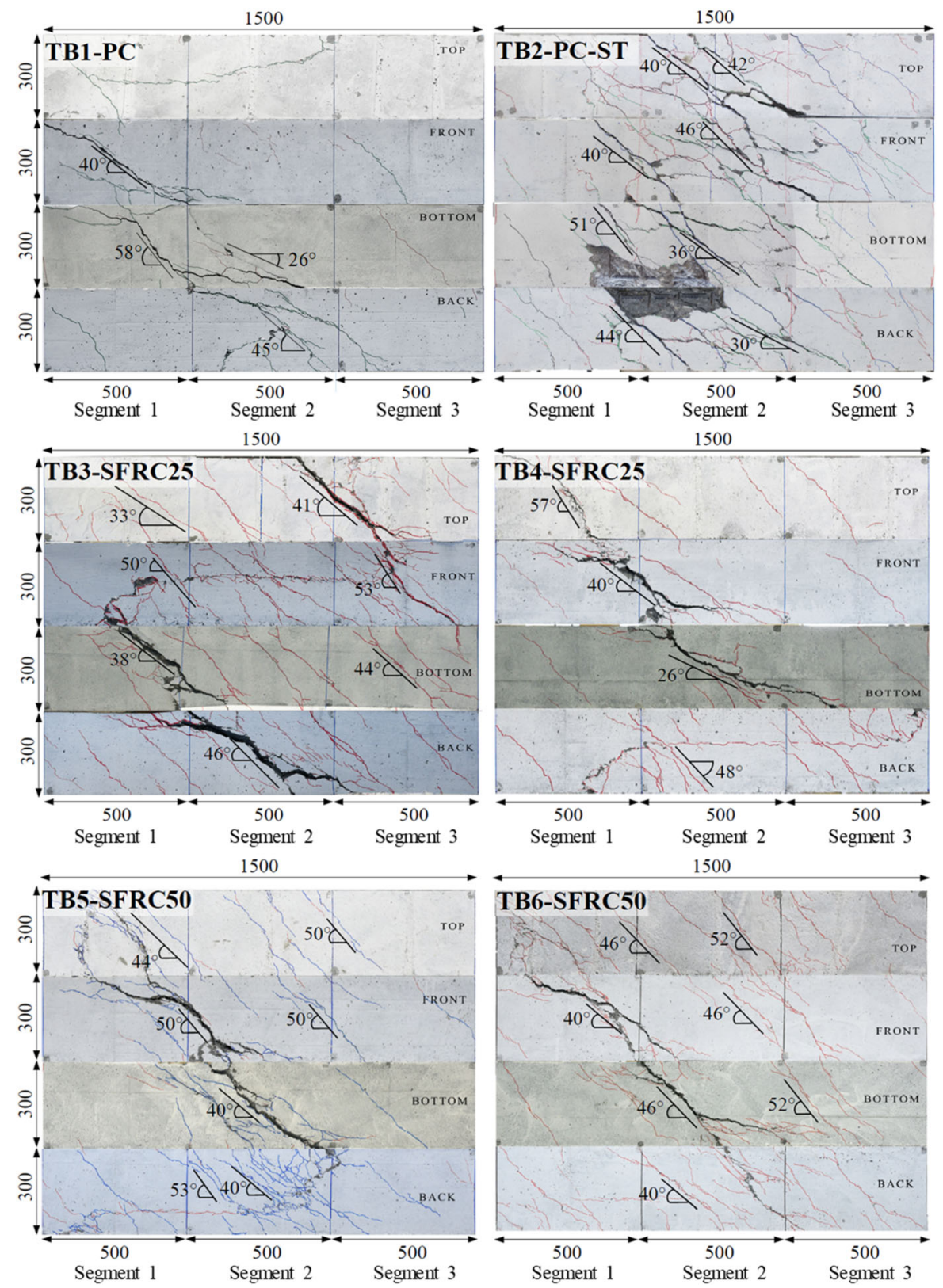

Fig. 7 Final crack patterns of beam specimens

"mean-segment" and "mean-side", report the crack widths obtained by averaging those observed in every single segment and side of the beam, respectively. Moreover, the torque and the related twist reported for each beam in Table 6 were chosen so that the overall mean crack width (i.e. average of the mean values of each segment and side) was approximately equal to
$0.3 \mathrm{~mm}$. The latter is generally considered as a permissible (or maximum design) crack width for concrete structures under service loading conditions.

TB2-PC-ST exhibited cracks of about $0.3 \mathrm{~mm}$ when the twist and the corresponding torque were equal to $20 \mathrm{rad} / \mathrm{m}$ and $18.8 \mathrm{kNm}$. Compared to TB2PC-ST, all SFRC beams recorded higher torques 
Table 6 Torque and twist corresponding to average crack widths $\left(\mathrm{w}_{\mathrm{m}}\right)$ of about $0.3 \mathrm{~mm}$

\begin{tabular}{|c|c|c|c|c|c|}
\hline \multirow{2}{*}{$\begin{array}{l}\text { Specimen } \\
\text { Torque }(\mathrm{kNm}) \\
\text { Twist }(\mathrm{rad} / \mathrm{m})\end{array}$} & \multirow[t]{2}{*}{ Side } & \multicolumn{3}{|l|}{$\mathrm{w}_{\mathrm{m}}(\mathrm{mm})$} & \multirow[t]{2}{*}{ Mean-side } \\
\hline & & Segment 1 & Segment 2 & Segment 3 & \\
\hline TB2-PC-ST & Top & 0.25 & 0.29 & 0.31 & 0.28 \\
\hline$T=18.8$ & Front & 0.38 & 0.25 & 0.17 & 0.27 \\
\hline \multirow[t]{2}{*}{$\Psi=20$} & Bottom & 0.18 & 0.28 & 0.34 & 0.27 \\
\hline & Rear & 0.28 & 0.39 & 0.34 & 0.34 \\
\hline Mean-segment & & 0.27 & 0.30 & 0.19 & 0.30 (side-segment) \\
\hline TB3-SFRC25 & Top & 0.10 & 0.49 & 0.45 & 0.35 \\
\hline$T=27.3$ & Front & 0.17 & 0.37 & 0.28 & 0.27 \\
\hline \multirow[t]{2}{*}{$\Psi=19$} & Bottom & 0.09 & 0.45 & 0.44 & 0.33 \\
\hline & Rear & 0.08 & 0.44 & 0.16 & 0.23 \\
\hline Mean-segment & & 0.11 & 0.44 & 0.33 & 0.30 (side-segment) \\
\hline TB4-SFRC25 & Top & 0.30 & 0.27 & 0.46 & 0.34 \\
\hline$T=22.5$ & Front & 0.42 & 0.42 & 0.44 & 0.42 \\
\hline \multirow[t]{2}{*}{$\Psi=13$} & Bottom & 0.13 & 0.51 & 0.22 & 0.29 \\
\hline & Rear & 0.13 & 0.15 & 0.07 & 0.12 \\
\hline Mean-segment & & 0.24 & 0.34 & 0.30 & 0.30 (side-segment) \\
\hline TB5-SFRC50 & Top & 0.17 & 0.20 & 0.13 & 0.17 \\
\hline$T=26.6$ & Front & 0.49 & 0.46 & 0.31 & 0.42 \\
\hline \multirow[t]{2}{*}{$\Psi=16$} & Bottom & 0.49 & 0.67 & 0.09 & 0.42 \\
\hline & Rear & 0.14 & 0.19 & 0.11 & 0.15 \\
\hline Mean-segment & & 0.32 & 0.38 & 0.16 & 0.30 (side-segment) \\
\hline TB6-SFRC50 & Top & 0.22 & 0.31 & 0.06 & 0.20 \\
\hline$T=24.3$ & Front & 0.48 & 0.40 & 0.52 & 0.46 \\
\hline \multirow[t]{2}{*}{$\Psi=20$} & Bottom & 0.16 & 0.70 & 0.17 & 0.34 \\
\hline & Rear & 0.16 & 0.18 & 0.16 & 0.17 \\
\hline Mean-segment & & 0.25 & 0.40 & 0.23 & 0.30 (side-segment) \\
\hline
\end{tabular}

ranging from $22.5 \mathrm{kNm}$ (TB4-SFRC25) to $27.3 \mathrm{kNm}$ (TB3-SFRC25). As expected, the specimens characterized by the most diffused crack patterns (i.e., TB3SFRC25 and TB5-SFRC50) presented the highest increment of resistance (i.e., $46 \%$ and $41 \%$ ) with respect to the beam with stirrups. At the same time, the beam with the lowest number of cracks, i.e. TB4SFRC25, experienced the lowest increment of resistance (i.e., 20\%). The internal stress redistribution due to cracking affected the torsional resistance as well as the twist capacity of the specimen. In fact, looking at the behavior of the SFRC beams, it appears that the higher the number of cracks, the higher the twist leading to the same crack width level. Therefore, TB3SFRC25 twisted $46 \%$ more than TB4-SFRC25 to reach a mean crack width value of $0.3 \mathrm{~mm}$.

\section{Discussion}

The conventional reinforcement placed in the specimen TB2-PC-ST according Eurocode 2 [21] was able to ensure a reserve of capacity after cracking that prevented a brittle failure. As shown in Fig. 4, the resisting torque after cracking remained greater than $T_{\text {cr }}$ and, in addition, $T_{\mathrm{p}} / T_{\text {cr }}(=1.56)$ was adequately high (Table 5). Based on the space truss analogy $[19,20]$, one may further demonstrate that failure was governed by yielding of stirrups. In fact, the resisting torque related to tensile failure of stirrups $\left(T_{\mathrm{p}, \mathrm{st}}\right)$ was significantly lower than those involving compression failure of the struts $\left(\mathrm{T}_{\mathrm{p}, \mathrm{str}}\right)$ and yielding of longitudinal reinforcement $\left(T_{\mathrm{p}, \mathrm{s}}\right)$ : 


$$
\begin{aligned}
T_{\mathrm{p}, \mathrm{st}} & =\frac{A_{\mathrm{sw}}^{\prime}}{s_{\mathrm{st}}} \cdot 2 \cdot A_{\mathrm{o}} \cdot f_{\mathrm{y}, \mathrm{st}} \cdot \cot g \theta=17.4 \mathrm{kNm} \\
T_{\mathrm{p}, \mathrm{str}} & =2 \cdot A_{\mathrm{o}} \cdot t_{\mathrm{c}} \cdot 0.5 f_{\mathrm{cm}} \cdot \frac{\cot g \theta}{1+(\cot g \theta)^{2}} \\
& =80.4 \mathrm{kNm}
\end{aligned}
$$

$$
T_{\mathrm{p}, \mathrm{sl}}=A_{s l} \cdot 2 \cdot \frac{A_{\mathrm{o}}}{p_{\mathrm{o}}} \cdot f_{\mathrm{y}, \mathrm{sl}} \cdot \operatorname{tg} \theta=64.0 \mathrm{kNm}
$$

In Eqs. 6-8, the inclination of the compressive struts $(\theta)$ is assumed equal to $40^{\circ}$. This corresponds to the mean inclination of the cracks detected for the beam TB2-PC-ST. In Eqs. $6-8, \mathrm{~A}_{\mathrm{sw}}{ }=28.3 \mathrm{~mm}^{2}$ is the area of one leg of a stirrup; $\mathrm{t}_{\mathrm{c}}=A_{\mathrm{c}} / p_{\mathrm{c}}=75 \mathrm{~mm}$ is the thickness of the equivalent thin-walled tube according Eurocode 2 [21]; $f_{\mathrm{cm}}=36 \mathrm{MPa}$ is the compressive strength of concrete (PC) without fibers (Table 3 ); $f_{\mathrm{y}, \mathrm{st}}=485 \mathrm{MPa}$ and $f_{\mathrm{y}, \mathrm{sl}}=516 \mathrm{MPa}$ are the yielding strengths of bars $\varnothing 6$ and $\varnothing 18$, respectively (Table 4). Note that the prediction of Eq. 6 $(17.4 \mathrm{kNm})$ is only $17 \%$ lower than the actual value observed in the test.

The results reported in the previous sections showed that fibers have the potential to replace the minimum required conventional transverse reinforcement to resist torsion. In fact, all the SFRC beams attained a torsional resistance $10-30 \%$ higher than TB2-PC-ST and, moreover, they experienced a twist capacity similar, or even higher, than that of TB2-PCST.

As typical of RC beams [3, 52], the beam TB2-PCST was affected by a substantial loss of torsional stiffness after cracking. This loss was significantly mitigated by fibers as the rigidity exhibited by SFRC beams right after first cracking was significantly higher. The ability of the fibers to control the torsional post-cracking stiffness of the members represents an important advantage for service loading conditions, as the reduced torsional deformation leads to much smaller crack widths. Beyond peak load, the beams containing fibers presented a stable and ductile behavior that was characterized by an almost constant torsional resistance for increasing rotations. The torsional resistance started to decrease once the twist achieved values slightly lower (18-20 rad/m), or even higher (30 rad/m for TB3-SFRC25 only), than the rotation at peak $(24.35 \mathrm{rad} / \mathrm{m})$ reached by TB2-PCST.
From the analysis of the experimental results reported herein it is premature to determine a definite relationship between the structural performance (i.e., resisting torque, deformation capacity, torsional stiffness, etc.) of the SFRC specimens and the corresponding fiber contents. Against expectations, the two beams containing the lowest amount of fibers (i.e., $25 \mathrm{~kg} / \mathrm{m}^{3}$ ) were those that displayed the best (TB3SFRC25) and the worst (TB4-SFRC25) behavior in terms of torsional capacity and toughness. An accurate study of the ultimate crack patterns can partly provide an explanation for the aforementioned responses. In fact, TB3-SFRC25 and TB4-SFRC25 were the beams with the most and the least diffused crack patterns at failure, respectively. Besides the quite consistent scatter of material tests reported in Table 3, the number of cracks developed during the test affected the ability of the specimens to redistribute internal stresses leading to differing structural performances. For the same reasons, the effect of the crack patterns of the two SFRC50 samples on their response was intermediate between those of the SFRC25 specimens. Other studies, including tests on beams having an overall length different from that adopted herein [53], reported a similar trend.

Table 7 provides a summary of selected data on pure torsion tests found in the literature. The beams reported in Table 2 are characterized by different longitudinal reinforcement ratios, varying from 0.25 to $1.57 \%$, and different fiber volume fractions, ranging from 0.32 to $3 \%$. All of the specimens experienced failure in tension (torsion-tension mechanism) as no stirrups were provided in any sample. The last column of Table 7 compares the fiber content of each beam with the minimum fiber volume fraction (i.e., $0.32 \%$ ) adopted in the present study. As one may observe, the maximum increment of torsional resistance after cracking, i.e., $T_{\mathrm{p}} / T_{\mathrm{cr}}=2.0$, is quite low if compared with the wide range of values $\rho_{\mathrm{f}} / \rho_{\mathrm{f}, \text { min }}=\rho_{\mathrm{f}} / 0.32 \%$, i.e., $\rho_{\mathrm{f}} / \rho_{\mathrm{f}, \min }=2.0-9.4$ (Table 7 ), that characterizes the increment of the fiber content. The same consideration can be stated for the increment of postcracking twist $\left(\Psi_{\mathrm{p}} / \Psi_{\mathrm{cr}}\right)$, which varied from 1.8 to 15.2. It is worth noting that, despite the low/moderate content of fibers adopted, the best performance was achieved by the beams tested in this research. This is probably due to the good tensile post-cracking behavior of the SFRC25 and SFRC 50, which contained steel fibers having geometrical and mechanical properties 
Table 7 Comparison of different research studies

\begin{tabular}{|c|c|c|c|c|c|c|c|c|}
\hline Authors & Specimen & $\mathrm{B}(\mathrm{mm})$ & $H(\mathrm{~mm})$ & $\rho_{1}(\%)$ & $\rho_{\mathrm{f}}(\%)$ & $T_{\mathrm{p}} / \mathrm{cr}(-)$ & $\rho_{\mathrm{f}} / 0.32 \% *(-)$ & $\Psi_{\mathrm{p}} / \Psi_{\mathrm{cr}}(-)$ \\
\hline \multirow[t]{4}{*}{ Present study } & TB3-SFRC25 & 300 & 300 & 1.13 & 0.32 & 2.0 & 1.0 & 14.1 \\
\hline & TB4-SFRC25 & 300 & 300 & 1.13 & 0.32 & 1.9 & 1.0 & 9.4 \\
\hline & TB5-SFRC50 & 300 & 300 & 1.13 & 0.63 & 1.9 & 2.0 & 15.2 \\
\hline & TB6-SFRC50 & 300 & 300 & 1.13 & 0.63 & 1.8 & 2.0 & 9.0 \\
\hline \multirow{8}{*}{$\begin{array}{l}\text { Narayanan and } \\
\text { Kareen-Palanjian [38] }\end{array}$} & LF1 & 85 & 178 & 1.34 & 1.34 & 1.4 & 4.2 & 6.7 \\
\hline & LF2 & 85 & 178 & 0.77 & 1.91 & 1.4 & 6.0 & 4.9 \\
\hline & LF3 & 85 & 178 & 0.77 & 1.34 & 1.4 & 4.2 & 4.9 \\
\hline & LF4 & 85 & 178 & 0.25 & 1.86 & 1.4 & 5.8 & 3.7 \\
\hline & LF6 & 85 & 178 & 0.52 & 1.59 & 1.4 & 5.0 & $* *$ \\
\hline & LF7 & 85 & 178 & 1.16 & 0.95 & 1.6 & 3.0 & $* *$ \\
\hline & LF8 & 85 & 85 & 1.56 & 1.06 & 1.4 & 3.3 & $* *$ \\
\hline & LF9 & 85 & 145 & 0.91 & 1.42 & 1.3 & 4.4 & $* *$ \\
\hline \multirow[t]{2}{*}{ Chalioris and Karayannis [41] } & RL1 & 100 & 200 & 1.57 & 1.00 & 1.3 & 3.1 & 1.8 \\
\hline & RL3 & 100 & 200 & 1.57 & 3.00 & 1.4 & 9.4 & 3.4 \\
\hline
\end{tabular}

$* \rho_{\mathrm{f}} / 0.32 \%$ : ratio between the volume fraction of fibers of the specimen and the minimum fraction of fibers (i.e. $0.32 \%$ ) that characterizes the samples reported in this table

**No data available

much better than those adopted by the other studies reported in Table 2. Unfortunately, the comparison is difficult since all other studies did not report any mechanical characterization of the SFRC.

Notwithstanding this, the results provided by the literature and reported in Table 7 represent an important reference point for the state of knowledge even though it remains an urgent need for new experimental research to improve the current knowledge about the torsional behavior of SFRC beams without stirrups.

\section{Concluding remarks}

The results of six large-scale beams subjected to pure torsion have been presented in this paper. Comparisons have been made between a sample with no stirrups nor fibers, one with the minimum classical reinforcement and the remaining four containing steel fibers. All specimens were longitudinally reinforced so that a space truss mechanism could be established. Based on the experiments and discussion reported herein, the following main conclusions can be drawn:

- FRC with a post-cracking performance higher than class 2c, according MC2010, is able to completely substitute the minimum transverse reinforcement required for torsion.

- FRC having performance class $2 \mathrm{c}$ was able to enhance the torsional behavior by increasing the torque at peak, the post-cracking torsional rigidity as well as the cumulative strain energy in comparison with the reference RC sample containing minimum conventional transverse reinforcement according Eurocode 2.

- Steel fibers are able to promote a significantly higher post-cracking rigidity and a steadier development of the cracking phenomenon, compared to classical RC elements. This phenomenon provides an enhanced behavior at serviceability limit states.

- From the discussion of the database of 14 experiments on SFRC specimens without torsional reinforcement, it seems that fibers enhance the torsional strength and, therefore, have the abilty to completing substituting transverse reinforcement required for torsion. Further specific studies are needed to validate this concept.

Acknowledgments The authors would like to thank Eng. Andrea Erculiani and Eng. Riccardo Tonoli for their contribution and support throughout the tests and data processing. A special thank goes also to the laboratory technicians Augusto Botturi, Andrea Del Barba and Luca 
Martinelli for their caring work. The fruitful discussion with Dr. Ali Amin is also gratefully acknowledged.

Funding Open Access funding provided by Università degli Studi di Brescia.

\section{Compliance with ethical standards}

Conflict of interest The authors declare that they have no conflict of interest.

Open Access This article is licensed under a Creative Commons Attribution 4.0 International License, which permits use, sharing, adaptation, distribution and reproduction in any medium or format, as long as you give appropriate credit to the original author(s) and the source, provide a link to the Creative Commons licence, and indicate if changes were made. The images or other third party material in this article are included in the article's Creative Commons licence, unless indicated otherwise in a credit line to the material. If material is not included in the article's Creative Commons licence and your intended use is not permitted by statutory regulation or exceeds the permitted use, you will need to obtain permission directly from the copyright holder. To view a copy of this licence, visit http://creativecommons.org/licenses/by/4.0/.

\section{References}

1. Mörsch E (1908) "Der Eisenbeton." Verlag von Konrad Wittwer, Stuttgart. pp 44-46

2. Graf O, Mörsch E (1922) Verdrehungsversuche zur Klärung der Schubfestigkeit von Eisenbeton. Verlag von Konrad Wittwer, Berlin

3. Lampert P, Thürlimann B (1968) "Torsionsversuche an Stahlbetonbalken", Bericht Nr6506-3. Institut für Baustatik, ETH, Züurich

4. Hsu TTC (1968) Torsion of structural concrete-behavior of reinforced concrete rectangular members. ACI Sympos Publ 18:261-306

5. Mitchell D, Collins MP (1974) The behavior of structural concrete beams in pure torsion. University of Toronto, Department of Civil Engineering, Publication 74-06

6. Liao HM, Ferguson PM (1969) Combined torsion in reinforced concrete L-beams with stirrups. ACI J Proc 66(12):986-993

7. Mansur MA, Paramasivam P (1985) Fiber reinforced concrete beams in torsion, bending, and shear. ACI J Proc 82(1):33-39

8. Hsu HL, Wang CL (2000) Flexural-torsional behaviour of steel reinforced concrete members subjected to repeated loading. Earthq Eng Struct Dyn 29(5):667-682

9. Chiu HJ, Fang IK, Young WT, Shiau JK (2007) Behavior of reinforced concrete beams with minimum torsional reinforcement. Eng Struct 29(9):2193-2205

10. Rasmussen LJ, Baker G (1995) Torsion in reinforced normal and high-strength concrete beams-part 1: experimental test series. ACI Struct J 92(1):56-62
11. Koutchoukali NE, Belarbi A (2001) Torsion of highstrength reinforced concrete beams and minimum reinforcement requirements. ACI Struct J 98(4):462-469

12. Fang IK, Shiau JK (2004) Torsional behavior of normal- and high-strength concrete beams. ACI Struct J 101(3):304-313

13. Chalioris CE (2008) Torsional strengthening of rectangular and flanged beams using carbon fibre-reinforced-polymers-experimental study. Constr Build Mater 22(1):21-29

14. Deifalla A, Ghobarah A (2010) Strengthening RC T-beams subjected to combined torsion and shear using FRP fabrics: EXPERIMENTAL study. J Compos Constr 14(3):301-311

15. Schladitz F, Curbach M (2012) Torsion tests on textilereinforced concrete strengthened specimens. Mater Struct 45(1-2):31-40

16. Rausch E (1929) Design of reinforced concrete for torsion and shear [in German]. (Berechnung des Eisenbetons gegen Verdhung und Abscheren). Julius Springer, Berlin, p 50

17. Lampert $P$ (1970) Ultimate strength of reinforced concrete beams in torsion and bending [in German]. (Bruchwiderstand von Stahlbetonbalken unter torsion und biegung). Ph.d. dissertation. Swiss Federal Institute of Technology, Zürich

18. Lampert P, Collins MP (1972) Torsion, bending and confusion-an attempt to establish the facts. ACI J 69(8):500-504

19. Park R, Paulay T (1975) Reinforced concrete structures. Wiley, London

20. Leonhardt F, Mönnig E (1973) Lectures on structural engineering - part I. fundamentals in the design of reinforced concrete construction. (Vorlesungen fiber Massivbau-Erster Teil. Grundlagen zur Bemessung in Stahlbetonbau). Springer, Berlin, pp 253-279

21. EN 1992-1-1: Eurocode 2 (2005) Design of concrete structures. Part 1-1: general rules and rules for buildings

22. ACI Committee 318-05 (2005) Building code requirements for reinforced concrete (ACI 318-05) and commentary (ACI 318R-05). American Concrete Institute, Farmington Hills

23. Choi KK, Hong-Gun P, Wight JK (2007) Shear strength of steel fiber-reinforced concrete beams without web reinforcement. ACI Struct J 104(1):12-21

24. Susetyo J, Gauvreau P, Vecchio FJ (2011) Effectiveness of steel fiber as minimum shear reinforcement. ACI Struct $\mathbf{J}$ 108(4):488-496

25. Minelli F, Plizzari GA (2013) On the effectiveness of steel fibers as shear reinforcement. ACI Struct J 110(3):379-389

26. Facconi L, Minelli F (2020) Behavior of lightly reinforced fiber reinforced concrete panels under pure shear loading. Eng Struct 202:109879

27. di Prisco M, Dozio D, Belletti B (2013) On the fracture behaviour of thin-walled SFRC roof elements. Mater Struct 46(5):803-829

28. Spinella N (2013) Shear strength of full-scale steel fibrereinforced concrete beams without stirrups. Comput Concr 11(5):365-382

29. Amin A, Foster SJ (2016) Shear strength of steel fibre reinforced concrete beams with stirrups. Eng Struct 111:323-332

30. Chiaia B, Fantilli AP, Vallini P (2009) Evaluation of crack width in FRC structures and application to tunnel linings. Mater Struct 42(3):339 
31. Tiberti G, Minelli F, Plizzari G (2014) Reinforcement optimization of fiber reinforced concrete linings for conventional tunnels. Compos B Eng 58:199-207

32. Liao L, de la Fuente A, Cavalaro S, Aguado A (2015) Design of FRC tunnel segments considering the ductility requirements of the model code 2010. Tunn Undergr Space Technol 47:200-210

33. di Prisco M, Martinelli P, Parmentier B (2016) On the reliability of the design approach for FRC structures according to fib model code 2010: the case of elevated slabs. Struct Concr 17(4):588-602

34. Blanco A, Pujadas P, De la Fuente A, Cavalaro SHP, Aguado A (2016) Influence of the type of fiber on the structural response and design of FRC slabs. J Struct Eng 142(9):04016054

35. Facconi L, Plizzari G, Minelli F (2019) Elevated slabs made of hybrid reinforced concrete: proposal of a new design approach in flexure. Struct Concr 20(1):52-67. https://doi. org/10.1002/suco.201700278

36. Mansur MA, Paramasivam P (1982) Steel fibre reinforced concrete beams in pure torsion. Int $\mathrm{J}$ Cement Compos Lighweight Concr 4(1):39-45

37. Narayanan R, Kareem-Palanjian AS (1983) Steel fibre reinforced concrete beams in torsion. Int J Cement Compos Lightweight Concr 5(4):235-246

38. Narayanan R, Kareem-Palanjian AS (1986) Torsion in beams reinforced with bars and fibers. J Struct Eng 112(1):53-66

39. Mansur MA, Nagataki S, Lee SH, Oosumimoto Y (1989) Torsional response of reinforced fibrous concrete beams. ACI Struct J 86(1):36-44

40. Rao TDG, Seshu DR (2003) Torsion of steel fiber reinforced concrete members. Cem Concr Res 33(11):1783-1788

41. Chalioris CE, Karayannis CG (2009) Effectiveness of the use of steel fibres on the torsional behaviour of flanged concrete beams. Cement Concr Compos 31(5):331-341

42. Yang IH, Joh C, Lee JW, Kim BS (2013) Torsional behavior of ultra-high performance concrete squared beams. Eng Struct 56:372-383
43. Fehling E, Ismail M (2012) Experimental investigations on UHPC structural elements subjected to pure torsion. In: Proceedings of the third international symposium on UHPC and nanotechnology for high performance construction materials, Kassel, Germany, pp 501-508

44. Amin A, Bentz EC (2018) Strength of steel fiber reinforced concrete beams in pure torsion. Structural Concrete 19(3):684-694

45. EN 12350-2 (2009) Testing fresh concrete. Slump-tests. European Standard

46. EN 206-1 (2006) Concrete-part 1: specification, performance, production and conformity, CEN

47. EN 14651 (2005) Test method for metallic concrete Measuring the flexural tensile strength (limit of proportionality (LOP), residual). EN 14651, European Committee for Standardization, Brussels, Belgium

48. fib Model code for concrete structures (2010) ISBN:978-3433-03061-5

49. ISO 15630-1 (2010) Steel for the reinforcement and prestressing of concrete-test methods-part 1: reinforcing bars, wire rod and wire

50. Collins MP, Mitchell D (1987) Prestressed concrete basics. Canadian Prestressed Concrete Institute, Ottawa

51. McMullen AE, EI-Degwy WM (1985) Prestressed concrete tests compared with torsion theories. J Prestress Concr Inst 30(5):96-127

52. Mitchell D, Collins MP (1978) Influence of prestressing on torsional response of concrete beams. PCI J 23(3):54-73

53. Facconi L, Minelli F, Plizzari G, Ceresa P (2019) Experimental study on steel fiber reinforced concrete beams under pure torsion. In: Derkowski W et al (eds) Proceedings of the fib symposium 2019 held in Kraków, Poland

Publisher's Note Springer Nature remains neutral with regard to jurisdictional claims in published maps and institutional affiliations. 